\title{
Effects of an Integrated Exercise Program Including "Functional” Inspiratory Muscle Training in Geriatric Individuals with and without Chronic Obstructive Pulmonary Disease
}

\author{
Ismail Ozsoy ${ }^{1}$, Buse Ozcan Kahraman ${ }^{2}$, Gulsah Ozsoy ${ }^{1}$, Nursen Ilcin ${ }^{2}$, Nil Tekin ${ }^{3}$, Sema Savci ${ }^{2}$ \\ ${ }^{1}$ Department of Physiotherapy and Rehabilitation, Faculty of Health Sciences, Selcuk University, Konya, Turkey \\ ${ }^{2}$ School of Physical Therapy and Rehabilitation, Dokuz Eylul University, Izmir, Turkey \\ ${ }^{3}$ Narlidere Nursing Home Elderly Care and Rehabilitation Center, Izmir, Turkey
}

\author{
Corresponding Author: \\ Ismail Ozsoy, $\mathrm{PhD}$ \\ Department of Physiotherapy and \\ Rehabilitation, Faculty of Health \\ Sciences, Selcuk University, Ardicli, \\ Celal Bayar Cd. No:299, Konya 42250, \\ Turkey \\ E-mail: ozsoy.ismail@yahoo.com \\ ORCID: \\ https://orcid.org/0000-0001-9048-1116
}

Received: January 24, 2021

Revised: March 11, 2021

Accepted: March 15, 2021

The study was presented as a poster at the European Respiratory Society

Congress, held on September 15-19,

2018 in Paris, France.

\begin{abstract}
Background: Inspiratory muscle training (IMT) is a commonly used exercise method for both patients with chronic obstructive pulmonary disease (COPD) and the older adult population. In addition to their primary function, respiratory muscles play an active role in core stabilization. However, no IMT program includes both of these functions (i.e., core stabilization and postural control functions as well as respiration). This study investigated the effects of a newly integrated exercise program, termed "functional IMT," in geriatric individuals with and without COPD. Methods: This prospective and experimental study included 45 geriatric individuals with COPD $(n=22)$ and without COPD $(n=23)$. The training program consisted of 4 weeks of conventional IMT followed by 4 weeks of functional IMT. Respiratory muscle strength, symptoms, exercise capacity, balance, postural control, physical activity, and quality of life were evaluated. Results: After training, respiratory muscle strength, symptoms, exercise capacity, balance, postural control, and quality of life improved in both groups $(p<0.05)$. In addition, physical activity was increased in the COPD group $(p<0.05)$. We observed no statistically significant difference in outcomes between the two groups before and after treatment $(p>0.05)$. Conclusion: The gains were similar in both groups. Functional IMT, which is an integrated approach that includes all respiratory muscle functions, is a safe, effective, and innovative method for use in geriatric individuals with and without COPD.
\end{abstract}

Key Words: Chronic obstructive pulmonary disease, Exercise, Respiratory muscles

\section{INTRODUCTION}

The incidence of chronic obstructive pulmonary disease (COPD), one of the most important causes of worldwide mortality and morbidity, increases with age; moreover, the disease worsens with aging. ${ }^{1)}$ Airflow obstruction in COPD causes problems with lung hyperinflation and blood gas exchange, a condition that increases respiratory workload. When respiratory muscles cannot meet the demand, dyspnea causes exercise intolerance and eventually leads to physical inactivity. ${ }^{2)}$ Aging increases physical impairment that results in functional disability. ${ }^{3}$

Respiratory muscles are skeletal muscles that must maintain continuous activity to ensure life. ${ }^{4)}$ Similar to other skeletal muscles, respiratory muscles can also be trained based on the principles of exercise. ${ }^{5)}$ Inspiratory muscle training (IMT) is an exercise method used for both patients with COPD and the older adult population, with positive effects in both populations. ${ }^{6-8)}$

However, in these studies, the IMT (also known as "foundation or conventional IMT") focused only on the respiratory task of respiratory muscles. In addition to their basic task of respiration, re- 
spiratory muscles are involved in core stabilization and postural control. .) $^{9}$ The motor activities of all trunk muscles, including the diaphragm, during both postural and respiratory tasks are coordinated by the central nervous system. The regulation of abdominal pressure occurs through coordinated activities of the abdominal, diaphragm, and pelvic floor muscles, and such modulation is important for postural control and spinal stability. ${ }^{9)}$ Moreover, balance and postural control are impaired in patients with COPD. 10,11)

The idea of a newly integrated exercise program that includes functional IMT, which includes all inspiratory muscle functions, was first proposed by McConnell. ${ }^{5)}$ This program aims to increase the gains by applying exercises addressing all muscle functions, ${ }^{5)}$ whereas foundation IMT mainly targets respiration. However, the contributions of the respiratory muscles to postural control and core stabilization have not been directly addressed in a rehabilitation context. To our knowledge, no previous study has directly assessed the effects of respiratory muscle training together with non-respiratory functions (core stabilization and postural control) in COPD and geriatric rehabilitation programs. Thus, this study aimed to create and investigate the effects of an integrated IMT program for geriatric individuals with and without COPD.

\section{MATERIALS AND METHODS}

\section{Study Design and Participants}

This prospective experimental study included 45 geriatric individuals (age $\geq 65$ years) with COPD $(n=22)$ and without COPD $(\mathrm{n}=23)$ (ClinicalTrials.gov Identifier: NCT04460261). The training program was identical for both groups and consisted of 4 weeks of foundation IMT followed by 4 weeks of functional IMT. Normal spirometry values were set as the inclusion criteria for healthy older adults. The study was announced to healthy older adults via social media and brochures. The Global Initiative for Chronic Obstructive Pulmonary Disease (GOLD) guidelines were used to diagnose COPD. The inclusion criterion for patients with COPD was the diagnosis of COPD—forced expiratory volume in $1 \mathrm{sec}$ ond $\left(\mathrm{FEV}_{1}\right) /$ forced vital capacity $(\mathrm{FVC})$ ratio $<0.7$ after bronchodilator administration. At the time of the study, all patients with COPD were in a stable clinical condition (same medication routine for the past 3 weeks without taking any antibiotics). Patients with neurological, orthopedic, or cognitive problems were excluded from the study.

All procedures performed in studies involving human participants or human tissue were conducted according to the ethical standards of the Institutional Ethical Review Board of Dokuz Eylul University (No. 2017/21-50) and the 1975 Declaration of Helsin- ki and its later amendments or comparable ethical standards. Informed consent was obtained from all participants included in the study.

\section{Outcome Measures}

The evaluations were conducted over 2 days. In particular, balance and postural control and exercise capacity tests were conducted on separate days. All performance tests were performed twice to eliminate the learning effect and ensure measurement accuracy.

A computer-based spirometer (Minispir; Medical International Research, Rome, Italy) was used to assess pulmonary function. ${ }^{12)}$

\section{Primary outcome measures}

Inspiratory and expiratory muscle strength: Inspiratory muscle strength (maximal inspiratory pressure [MIP]) and expiratory muscle strength (maximal expiratory pressure $[\mathrm{MEP}]$ ) were measured using a handheld mouth pressure device (Micro RMP; Micro Medical, Rochester, UK). Three to five acceptable and reproducible maximal maneuvers (i.e., differences between values $<10 \%$ ) were performed, and the highest value was recorded. ${ }^{13)}$

\section{Secondary outcome measures}

Symptoms: The modified Medical Research Council (mMRC) Dyspnea Scale was used to evaluate dyspnea. Commonly used in the assessment of dyspnea in COPD patients, the mMRC has a five-level scoring system ranging from 0 to 4 , in which a high score indicates an increased sense of dyspnea. ${ }^{14)}$

The COPD Assessment Test (CAT) was used to assess symptoms in patients with COPD. The CAT has eight items, with scores ranging from 0 to 40 . Higher scores indicate increased symptoms. ${ }^{15)}$ Functional exercise capacity: The 6-minute walking test (6MWT) and the 6-minute pegboard and ring test (6PBRT) were performed to assess functional exercise capacity. The $6 \mathrm{MWT}$ was performed according to American Thoracic Society guidelines ${ }^{16)}$ as follows. The $6 \mathrm{MWT}$ was performed on a $32-\mathrm{m}$ continuous track. The 6PBRT was performed as described by Zhan et al. ${ }^{17)}$ to assess unsupported upper-extremity exercise capacity.

Balance and postural control: Balance was assessed using the Berg Balance Scale (BBS). This scale consists of 14 items, each of which is scored between 0 and 4 , with higher scores indicating a better balance. ${ }^{18)}$ A portable balance device (Biodex Biosway Portable Balance System, New York, NY, USA) was used to measure static postural stability. A total of three measurements, each for 20 seconds, with a rest period of 10 seconds between measurements, were performed, with higher scores indicating impaired postural control. $^{19)}$

Physical activity: Physical activity was assessed using the Physical 
Activity Scale for the Elderly (PASE), a validated 12-item self-administered scale, in which higher scores indicated increased physical activity. $^{20)}$

Quality of life: Quality of life was assessed using the World Health Organization Quality of Life Instrument-Older Adults Module (WHOQOL-OLD). This questionnaire consists of 24 items in six different domains, with higher scores indicating a better quality of life. ${ }^{21)}$

\section{Treatment Programs}

We divided participants into two groups based on the presence or absence of COPD. Both groups underwent a total of 8 weeks of IMT using a threshold pressure loading device (POWERbreathe Classic Light Resistance; IMT Technologies Ltd., Birmingham, UK). The participants were asked to perform IMT twice daily in the morning and evening. Both groups were trained 3 days a week under physiotherapist supervision and without supervision on the other days of the week. The exercise duration and frequency were recorded in a diary. This study required that participants attend at least 80 prescribed exercise sessions. The treatment program consisted of 4 weeks of foundation IMT followed by 4 weeks of functional IMT.

\section{IMT Intensity}

The intensity of the exercise was adjusted to $40 \%-50 \%$ of the MIP. After 10 consecutive breathing cycles, the participants were asked to perform 3-4 breath controls. As tolerance increased, the number of consecutive respiratory cycles increased. The IMT intensity was adjusted using weekly MIP measurements (Table 1).

\section{Foundation IMT}

Foundation IMT is commonly used to train respiratory muscles.

Table 1. IMT programs

\begin{tabular}{ll}
\hline & \multicolumn{1}{c}{ DeSCRIption } \\
\hline Duration & Foundation IMT: 4 weeks \\
& Functional IMT: 4 weeks \\
Foundation IMT: Weeks 1-2, MIP 40\%; weeks 3-4, & MIP 50\% \\
Functional IMT: Weeks 5-6, MIP 40\%; weeks 7-8, & MIP 50\% \\
Two times daily in the morning and evening \\
Time & A total of 30 minutes per day \\
Number of repetitions & 10 consecutive breathing cycles (3-4 breath control) \\
& A gradually increasing number of cycles depending \\
on tolerance & The IMT intensity was adjusted according to weekly \\
MIP measurements
\end{tabular}

IMT, inspiratory muscle training; MIP, maximal inspiratory pressure (inspiratory muscle strength).
The present study applied foundation IMT during the first 4 weeks of training. We asked participants to sit in a comfortable upright position. We then placed a nose clip and instructed the patients to tighten their lips around the mouthpiece and breathe against the resistance. During this 4-week-long training, all IMT was performed solely in a sitting position, without any loading in other positions.

\section{Functional IMT}

After the foundation IMT, all participants underwent 4 weeks of functional IMT. Initially, all participants were taught diaphragmatic breathing and activation of the abdominal wall musculature. Each training session started with warm-up exercises and ended with cool-down exercises. During the loading phase, core stability, dynamic trunk activation, and postural control exercises were applied together with the IMT. The contents of the exercise program are shown in Table 2 and Fig. 1.

\section{Sample Size}

To our knowledge, no other study has investigated the effects of functional IMT in geriatric individuals with and without COPD. However, a previous study showed that IMT increased MIP in older individuals (baseline MIP, $82 \pm 27 \mathrm{cmH}_{2} \mathrm{O}$; post-intervention MIP, $\left.103 \pm 23 \mathrm{cmH}_{2} \mathrm{O}\right)^{22)}$ Based on these results, we calculated a minimum required sample size of 18 patients per group for an effect size of 0.83 . A probability level of 0.05 , and a statistical power level of $90 \%$ using G* Power Software (ver. 3.1.9.2; Düsseldorf, Germany). Allowing for a $20 \%$ dropout rate, this study included 45 participants.

\section{Data Analysis}

We analyzed the data using IBM SPSS Statistics for Windows version 20.0. (IBM Corp., Armonk, NY, USA). Shapiro-Wilk tests and histograms were used to check for normality of the data distributions. Values are expressed as mean \pm standard deviation and median (25th-75th quartiles) for continuous variables and as frequencies for categorical variables. Independent samples t-test (when samples met parametric conditions) and Mann-Whitney $\mathrm{U}$ test (when samples did not meet parametric conditions) were used to compare continuous variables between the two groups. Chi-square tests were used to compare categorical variables between the two groups. Paired-sample t-test (when samples met parametric conditions) and Wilcoxon signed-rank test (when samples did not meet parametric conditions) were used to determine the mean differences between before and after treatment. 
Table 2. Content of the functional IMT program

\begin{tabular}{|c|c|c|c|}
\hline & Description & Exercise time & Remark \\
\hline \multirow[t]{2}{*}{ Warm-up } & Diaphragmatic breathing exercises & 5-10 minutes & At the same time IMT \\
\hline & Flexibility exercises & & \\
\hline \multirow[t]{3}{*}{ Core stability exercises } & Plank on the wall & 60 seconds, 3 sets & \\
\hline & Side bridge on the wall & 60 seconds, 3 sets & \\
\hline & Bridge on the wall & 60 seconds, 3 sets & \\
\hline \multirow[t]{3}{*}{ Dynamic trunk activation exercises with upper-extremity movements } & Shoulder flexion & $8-12$ reps, 2 sets & \\
\hline & Shoulder abduction & $8-12$ reps, 2 sets & \\
\hline & Trunk rotation & $8-12$ reps, 2 sets & \\
\hline \multirow[t]{3}{*}{ Postural control exercises } & Sit-stand & 6 reps, 2 sets & \\
\hline & Standing leg lift & 30 seconds, 2 sets & \\
\hline & Walking & 30 seconds, 3 sets & \\
\hline Cool-down & Flexibility exercises & 5 minutes & \\
\hline
\end{tabular}

IMT, inspiratory muscle training; MIP, maximal inspiratory pressure (inspiratory muscle strength).
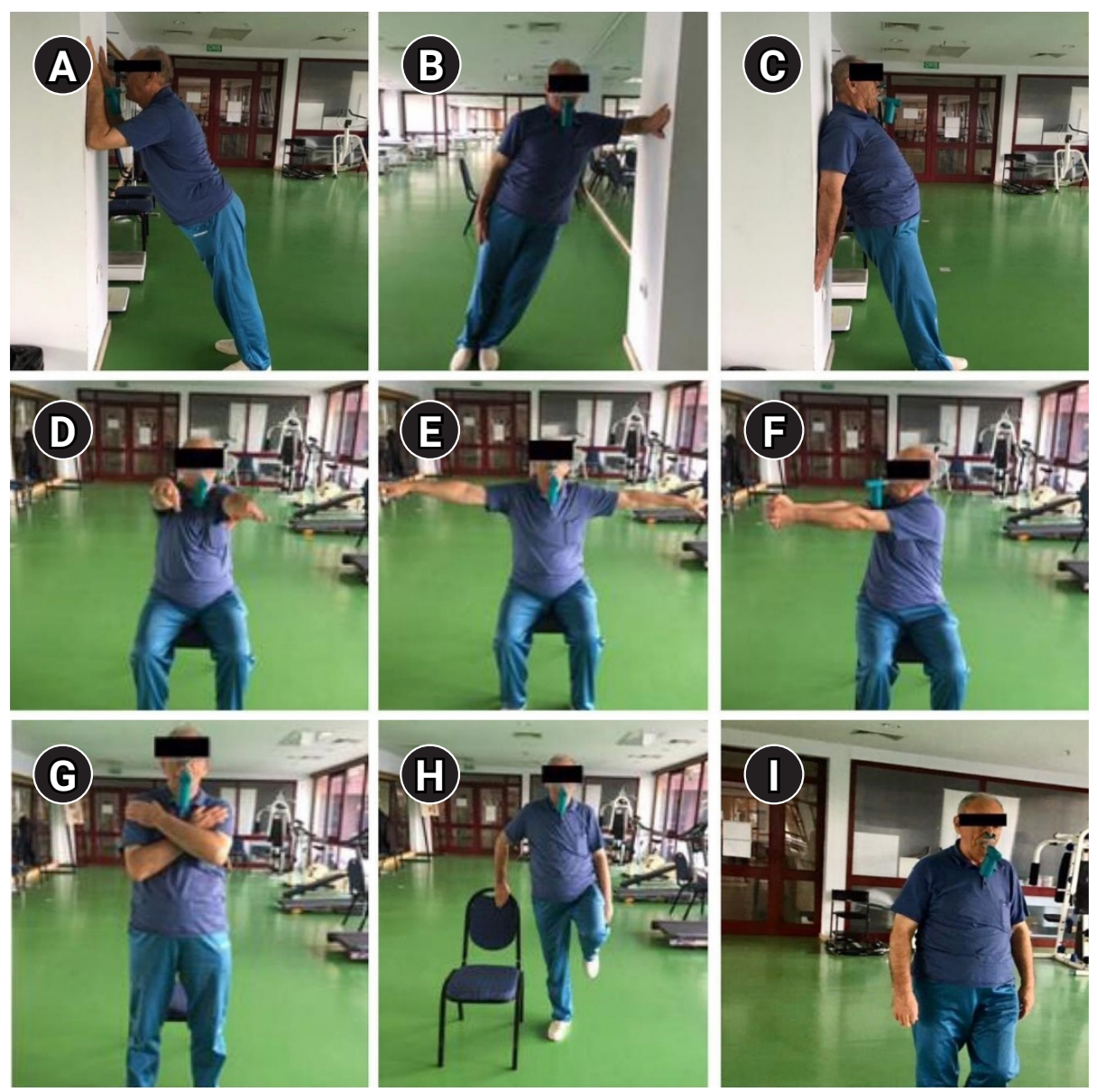

Fig. 1. The contents of the exercise program. Core stability exercises: (A) plank on the wall, (B) side bridge on the wall, and (C) bridge on the wall. Dynamic trunk activation exercises with upper-extremity movements: (D) shoulder flexion, (E) shoulder abduction, and (F) trunk rotation. Postural control exercises: $(\mathrm{G})$ sit-stand, (H) standing leg lift, and (I) walking. 


\section{RESULTS}

This study included a total of 45 geriatric individuals (COPD group, $n=22$; non-COPD group, $n=23$ ). Three participants in the COPD group and two in the non-COPD group dropped out. Hence, the study was completed with 19 and 21 participants in the COPD and non-COPD groups, respectively (Fig. 2).

The demographic characteristics (age, sex, weight, height, and body mass index) and cognitive status (Mini-Mental State Examination score) were similar between the groups ( $p>0.05)$ (Table 3).

Pulmonary function, respiratory muscle strength (except MIP\%), exercise capacity, balance, postural control (except anterior/posterior [score]), physical activity, and quality of life were significantly higher in the non-COPD group than in the COPD group, while symptom scores were significantly higher in the COPD group than in the non-COPD group (all p<0.05) (Table 3 ).

After training, respiratory muscle strength, symptom perception, exercise capacity, balance, postural control, and quality of life were significantly improved in both groups $(\mathrm{p}<0.05)$ (Table 4$)$. Additionally, physical activity was increased in the COPD group $(\mathrm{p}<0.05)($ Table 4).

We observed no statistically significant differences in respiratory muscle strength, symptom perception, exercise capacity, balance, postural control, physical activity, and quality of life between the groups before and after treatment $(\mathrm{p}>0.05)$ (Table 4$)$.

\section{DISCUSSION}

This is the first study to investigate the effects of a new integrated exercise program, called functional IMT, in geriatric individuals

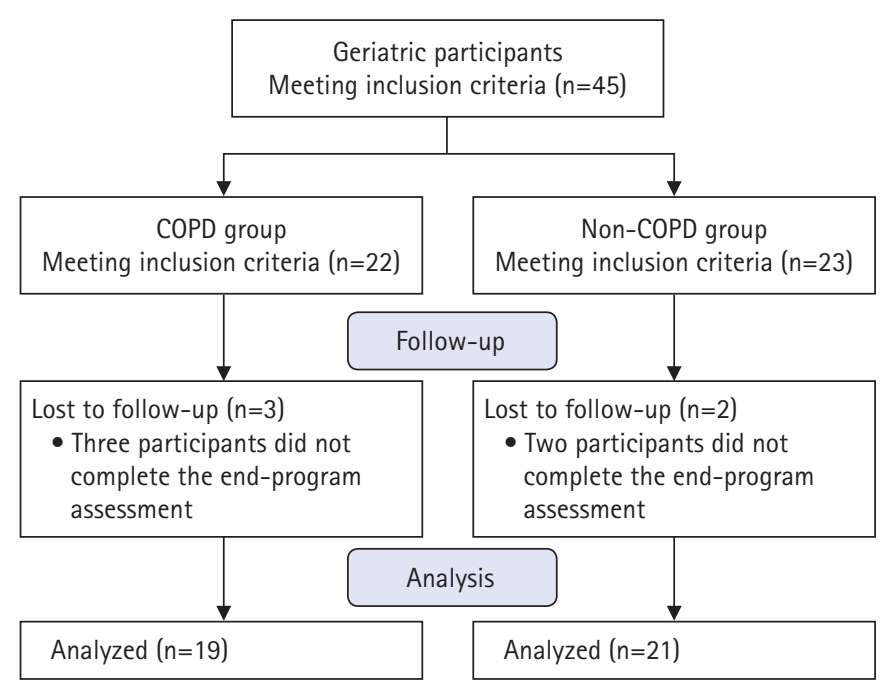

Fig. 2. Study flow diagram. COPD, Chronic obstructive pulmonary disease. with and without COPD. After the intervention, the gains were similar between groups. In the literature, IMT for COPD patients and geriatric people has focused solely on the respiratory tasks of the inspiratory muscles. However, the inspiratory muscles are also involved in core stabilization and postural control. Muscle training should include all muscle functions for optimal gain. Thus, the training program in the present study included all inspiratory muscle functions, i.e., both respiration and core stabilization.

In our study, 4 weeks of foundation IMT was followed by 4 weeks of functional IMT. The most important indication for IMT is the disturbance of supply/demand balance owing to increased respiratory workload. Increased demand for respiration leads to increased loading of respiratory muscles to meet these needs. In such situations, the respiratory muscles are mainly involved in their primary task of breathing, with their postural stabilization/control functions secondary to the primary task. Enhancing the optimal gain from a muscle training program requires functional training. Functional loading of the respiratory muscles while they lack the strength to perform their primary task of breathing will lead to failure of the muscles to perform optimally. Therefore, we initially applied foundation IMT to strengthen the muscles for respiration. Functional IMT was administered only when the adaptive process was completed. ${ }^{5)}$

Respiratory muscle training is an exercise method frequently employed for individuals with COPD. ${ }^{23,24)}$ A review investigating the effects of IMT in individuals with COPD reported that the treatment increased inspiratory muscle strength. ${ }^{23)}$ Furthermore, both inspiratory and expiratory muscle strengths improve with IMT. $^{25)}$ Souza et al. ${ }^{8)}$ reported increased diaphragm mobility and thickness and improved inspiratory and expiratory muscle strength in geriatric women following IMT. Another study conducted in a geriatric population showed the development of inspiratory muscle strength with IMT. ${ }^{22)}$ Consistent with the literature showing the positive effects of IMT, functional IMT in our study increased both inspiratory and expiratory muscle strength in geriatric individuals with and without COPD. However, the gains were similar in both groups.

Respiratory muscle weakness plays a predominant role in the development of dyspnea. ${ }^{2)}$ Therefore, studies of COPD often evaluate dyspnea as an outcome measure. Two large systematic reviews examining the effects of IMT on individuals with COPD showed that IMT reduced dyspnea. ${ }^{23,24)}$ In our study, we observed decreased mMRC scores after 8 weeks of IMT, consistent with previous findings. We also observed a decrease in CAT scores after treatment, indicating that functional IMT can reduce dyspnea and general symptom perception in patients with COPD. The effects of IMT in geriatric individuals are mostly assessed relative to respi- 
Table 3. Demographic and clinical characteristics

\begin{tabular}{|c|c|c|c|}
\hline & COPD group & Non-COPD group & $\mathrm{p}$-value \\
\hline Age (y) & $78.0(72.0-85.0)$ & $75.0(70.0-79.0)$ & $0.270^{\mathrm{a})}$ \\
\hline Sex & & & $0.962^{c)}$ \\
\hline Male & 58 & 57 & \\
\hline Female & 42 & 43 & \\
\hline Weigh (kg) & $72.7 \pm 10.7$ & $74.0 \pm 12.2$ & $0.740^{\mathrm{b})}$ \\
\hline Height $(\mathrm{cm})$ & $164.7 \pm 9.5$ & $164.6 \pm 8.9$ & $0.955^{\mathrm{b})}$ \\
\hline BMI $\left(\mathrm{kg} / \mathrm{m}^{2}\right)$ & $24.9(24.1-29.4)$ & $27.1(24.3-28.8)$ & $0.361^{a)}$ \\
\hline \multicolumn{4}{|l|}{ GOLD stage } \\
\hline II & 13 & - & \\
\hline III & 6 & - & \\
\hline MMSE score & $27.0(27.0-28.0)$ & $28.0(27.0-28.0)$ & $0.525^{\mathrm{a})}$ \\
\hline \multicolumn{4}{|l|}{ Pulmonary function } \\
\hline $\mathrm{FEV}_{1}(\%$ predicted $)$ & $57.2 \pm 12.2$ & $101.3 \pm 26.5$ & $\left.<0.001^{*}, \mathrm{~b}\right)$ \\
\hline FVC (\% predicted) & $72.7 \pm 13.5$ & $93.5 \pm 23.0$ & $\left.0.001^{*}, \mathrm{~b}\right)$ \\
\hline $\mathrm{FEV}_{1} / \mathrm{FVC}$ & $64.9(53.7-66.2)$ & $82.4(80.8-89.1)$ & $<0.001^{*, a)}$ \\
\hline PEF (\% predicted) & $52.0(40.0-76.0)$ & $93.0(68.5-130.5)$ & $<0.001^{*, a)}$ \\
\hline $\mathrm{FEF}_{25-75 \%}(\%$ predicted $)$ & $38.0(25.0-61.0)$ & $95.0(83.0-156.0)$ & $<0.001^{*, a)}$ \\
\hline \multicolumn{4}{|l|}{ Respiratory muscle strength } \\
\hline $\operatorname{MIP}\left(\mathrm{cmH}_{2} \mathrm{O}\right)$ & $43.0(35.0-79.0)$ & $58.0(47.0-79.0)$ & $0.031^{*, a)}$ \\
\hline $\operatorname{MIP}(\%)$ & $72.5(55.0-98.0)$ & $88.1(72.9-112.9)$ & $0.068^{\mathrm{a})}$ \\
\hline $\operatorname{MEP}\left(\mathrm{cmH}_{2} \mathrm{O}\right)$ & $72.0(50.0-105.0)$ & $100.0(75.0-138.0)$ & $0.036^{*, a)}$ \\
\hline $\operatorname{MEP}(\%)$ & $56.8 \pm 19.4$ & $75.1 \pm 28.7$ & $0.025^{*, b)}$ \\
\hline \multicolumn{4}{|l|}{ Symptoms } \\
\hline mMRC (score) & $2.0(2.0-3.0)$ & $1.0(0.0-1.0)$ & $<0.001^{*, a)}$ \\
\hline CAT (score) & $14.8 \pm 5.3$ & - & \\
\hline \multicolumn{4}{|l|}{ Exercise capacity } \\
\hline 6MWT distance $(\mathrm{m})$ & $350.0(280.0-393.8)$ & $455.0(358.8-490.0)$ & $0.012^{*, a)}$ \\
\hline 6MWT distance (\%) & $61.9 \pm 13.6$ & $74.3 \pm 12.3$ & $0.004^{*, b)}$ \\
\hline 6PBRT (score) & $111.9 \pm 27.7$ & $140.3 \pm 27.9$ & $0.003^{*, b)}$ \\
\hline \multicolumn{4}{|l|}{ Balance and postural control } \\
\hline \multicolumn{4}{|l|}{ Balance } \\
\hline BBS (0-56) & $47.6 \pm 3.3$ & $50.3 \pm 3.6$ & $0.022^{*, b)}$ \\
\hline \multicolumn{4}{|l|}{ Static postural stability } \\
\hline A/P stability index (score) & $0.5(0.4-0.6)$ & $0.4(0.3-0.6)$ & $0.111^{\mathrm{a})}$ \\
\hline M/L stability index (score) & $0.3(0.2-0.5)$ & $0.2(0.1-0.3)$ & $0.018^{*, a)}$ \\
\hline Overall stability index (score) & $0.6(0.5-0.9)$ & $0.4(0.3-0.8)$ & $0.033^{*, 2}$ \\
\hline \multicolumn{4}{|l|}{ Physical activity and quality of life } \\
\hline PASE (score) & $68.3 \pm 30.4$ & $100.0 \pm 35.1$ & $0.004^{*, b)}$ \\
\hline WHOQOL-OLD (score) & $54.2(47.9-58.3)$ & $66.7(63.5-72.4)$ & $<0.001^{* \text {,a) }}$ \\
\hline
\end{tabular}

Values are expressed as mean \pm standard deviation or median (25-75 quartiles) for continuous variables and frequencies were reported for categorical variables. COPD, Chronic obstructive pulmonary disease; BMI, body mass index; GOLD, Global Initiative for Chronic Obstructive Pulmonary Disease; MMSE, MiniMental State Examination; FVC, forced vital capacity; $\mathrm{FEV}_{1}$, forced expiratory volume in 1 second; PEF, peak expiratory flow rate; $\mathrm{FEF}_{25-75 \%}$, forced expiratory flow between 25\% and 75\% of FVC; MIP, maximal inspiratory pressure; MEP, maximal expiratory pressure; mMRC, modified Medical Research Council; CAT, COPD Assessment Test; 6MWT, 6-minute walk test; 6PBRT, 6-minute pegboard and ring test; BBS, Berg Balance Scale; A/P, anterior/posterior; M/L, medial/ lateral; PASE, Physical Activity Scale for the Elderly; WHOQOL-OLD, World Health Organization Quality of Life Instrument-Older Adults Module. ${ }^{*} \mathrm{p}<0.05$.

${ }^{\text {a) }}$ Mann-Whitney U test, ${ }^{\text {b) }}$ Student $t$-test, ${ }^{\text {c) }}$ chi-square test. 


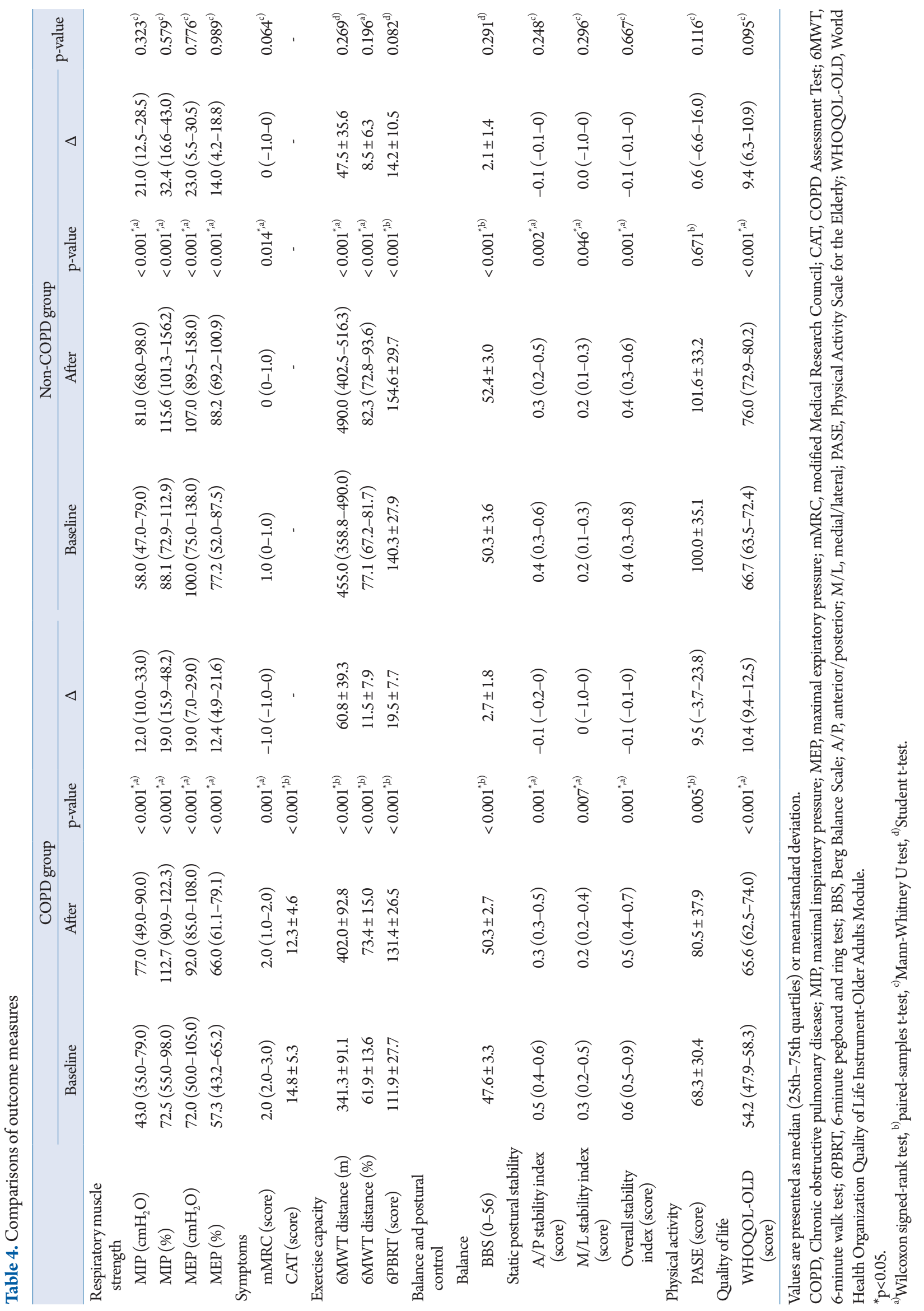


ratory muscle strength and exercise capacity; however, a study investigating the effects on dyspnea reported decreased dyspnea after 6 weeks of training. ${ }^{26)}$ Consistent with the literature, we observed decreased dyspnea following functional IMT in geriatric individuals. However, the difference between the two groups was not statistically significant. These results suggest that functional IMT is an effective method for reducing dyspnea in geriatric individuals with and without COPD.

Functional exercise capacity is one of the most important outcome measures in IMT studies of individuals with COPD. ${ }^{23)}$ There are inconsistent results regarding the effects of IMT on $6 \mathrm{MWT}$ distance in geriatric individuals. One study reported significant improvements in 6MWT and 12MWT results in the IMT group compared to those in the control group. ${ }^{23)}$ In contrast, Mills et al. reported no change in 6MWT distance after an 8-week-long IMT in 65- to 75 -year-old individuals. ${ }^{22)}$ However, Huang et al. ${ }^{26)}$ reported that functional exercise capacity improved after 6 weeks of IMT in geriatric individuals without COPD. In our study, the 6MWT distance improved after the training program in both groups, indicating that functional IMT is an effective method to increase functional exercise capacity in geriatric individuals with and without COPD.

Studies on exercise capacity in COPD have generally focused on the lower extremities. However, the upper extremities play a key role in performing daily living activities. ${ }^{27)}$ Zhan et al. ${ }^{17)}$ reported that the 6PBRT was a valid and reliable test for individuals with COPD. However, no study has investigated the effect of IMT on 6PBRT in geriatric individuals with and without COPD. We found functional IMT to be an effective method for increasing the unsupported upper-extremity exercise capacity in geriatric individuals with and without COPD. One reason for this finding may be the increased efficiency of respiratory muscles in performing non-respiratory tasks owing to improved strength, which leads to higher exercise capacity in the arms. Decreased dyspnea may also contribute to improved exercise capacity of the upper extremities.

To our knowledge, no other studies have investigated the effects of IMT on balance and postural control in COPD and geriatric individuals, which makes comparisons difficult. In our study, functional IMT yielded similar gains in balance and postural control in geriatric individuals with and without COPD. Further studies on this subject are required.

Physical activity levels were significantly lower in individuals with COPD than in healthy controls. ${ }^{28)}$ Eight weeks of IMT reportedly decreased dynamic hyperinflation and consequently improved physical performance in patients with GOLD stage II-III COPD. ${ }^{29)}$ In our study, the PASE scores of the COPD group increased after the training program. This result shows that function- al IMT can improve physical activity in geriatric patients with COPD.

A study including geriatric individuals that evaluated physical activity using an accelerometer reported increased physical activity as a result of an 8-week-long IMT program. ${ }^{30)}$ In contrast with the literature, in our study, the physical activity scores of participants in the non-COPD group were similar before and after the training, which might be due to the differences in the method of evaluating physical activity.

Quality of life in older individuals is a multidimensional concept that is mainly based on perceived health and happiness. Quality of life is affected in patients with COPD; moreover, as the disease severity increases, there is a marked deterioration in the patient quality of life. ${ }^{31)}$ In the literature, quality of life is considered a main outcome of IMT. Two comprehensive reviews stated that IMT improved the quality of life of patients with COPD. ${ }^{23,24)}$ In our study, quality of life improved significantly in the COPD group, indicating that functional IMT can improve the quality of life in these patients.

Contradicting results have been reported regarding the effects of IMT on the quality of life of geriatric individuals. Mills et al. ${ }^{22)}$ concluded that 8 weeks of IMT did not affect the quality of life of geriatric individuals. The results of a study investigating the effects of IMT on the quality of life of physically active geriatric individuals observed no improvement in the quality of life score. ${ }^{32)}$ However, Huang et al. ${ }^{26)}$ studied the effects of 6 weeks of IMT in geriatric individuals and reported improved quality of life. In our study, participants in the non-COPD group showed a significant increase in quality of life scores, thus demonstrating that functional IMT can be effective in increasing the quality of life of geriatric individuals with or without COPD.

This study had some limitations. First, the study did not include a control group, which might have provided clearer information regarding treatment effectiveness. However, there were difficulties in designing treatment applications for the control group. The numerous options include control groups with sham IMT, foundation IMT, postural control, core stabilization, and no intervention. Regardless of the control group, we could not completely demonstrate the effectiveness of functional IMT. Further studies are required on this subject. Second, only acute effects of the training were investigated without any long-term follow-up.

In conclusion, this is the first study to investigate the effects of a newly integrated exercise program, functional IMT, in geriatric individuals with and without COPD. After the intervention, the gains were similar between the groups. Our results of the study suggest that functional IMT is safe and effective in geriatric individuals with and without $\mathrm{COPD}$. 


\section{ACKNOWLEDGMENTS}

\section{CONFLICT OF INTEREST}

The researchers claim no conflicts of interest.

\section{FUNDING}

None.

\section{AUTHOR CONTRIBUTION}

Conceptualization: IO, BOK, GO, NI, NT, SS; Data curation: IO, BOK, GO; Funding acquisition: IO, BOK, GO, NI, NT, SS; Investigation: IO, BOK; Methodology: IO, BOK, GO, NI, NT, SS; Project administration: IO, SS; Supervision: IO, BOK, GO, SS; Writing-original draft: IO, BOK, GO; Writing-review and editing: IO, NI, NT, SS.

\section{REFERENCES}

1. Incalzi RA, Scarlata S, Pennazza G, Santonico M, Pedone C. Chronic obstructive pulmonary disease in the elderly. Eur J Intern Med 2014;25:320-8.

2. Hill K, Jenkins SC, Hillman DR, Eastwood PR. Dyspnoea in COPD: can inspiratory muscle training help? Aust J Physiother 2004;50:169-80.

3. Cesari M. Physical frailty and sarcopenia: development of a framework for supporting interventions against incident mobility disability. Ann Geriatr Med Res 2017;21:42-8.

4. Sieck GC, Ferreira LF, Reid MB, Mantilla CB. Mechanical properties of respiratory muscles. Compr Physiol 2013;3:1553-67.

5. McConnell A. Respiratory muscle training: theory and practice. 1st ed. Edinburgh, UK: Churchill Livingstone; 2013.

6. Figueiredo RI, Azambuja AM, Cureau FV, Sbruzzi G. Inspiratory muscle training in COPD. Respir Care 2020;65:1189-201.

7. Beaumont M, Forget P, Couturaud F, Reychler G. Effects of inspiratory muscle training in COPD patients: a systematic review and meta-analysis. Clin Respir J 2018;12:2178-88.

8. Souza H, Rocha T, Pessoa M, Rattes C, Brandao D, Fregonezi G, et al. Effects of inspiratory muscle training in elderly women on respiratory muscle strength, diaphragm thickness and mobility. J Gerontol A Biol Sci Med Sci 2014;69:1545-53.

9. Hodges PW, Heijnen I, Gandevia SC. Postural activity of the diaphragm is reduced in humans when respiratory demand increases. J Physiol 2001;537(Pt 3):999-1008.

10. Janssens L, Brumagne S, McConnell AK, Claeys K, Pijnenburg M, Burtin C, et al. Proprioceptive changes impair balance control in individuals with chronic obstructive pulmonary disease. PLoS One 2013;8:e57949.
11. Janssens L, Brumagne S, McConnell AK, Claeys K, Pijnenburg M, Goossens N, et al. Impaired postural control reduces sit-tostand-to-sit performance in individuals with chronic obstructive pulmonary disease. PLoS One 2014;9:e88247.

12. Ranu H, Wilde M, Madden B. Pulmonary function tests. Ulster Med J 2011;80:84-90.

13. Neder JA, Andreoni S, Lerario MC, Nery LE. Reference values for lung function tests. II. Maximal respiratory pressures and voluntary ventilation. Braz J Med Biol Res 1999;32:719-27.

14. Perez T, Burgel PR, Paillasseur JL, Caillaud D, Deslee G, Chanez P, et al. Modified Medical Research Council scale vs Baseline Dyspnea Index to evaluate dyspnea in chronic obstructive pulmonary disease. Int J Chron Obstruct Pulmon Dis 2015;10:1663-72.

15. Jones PW, Harding G, Berry P, Wiklund I, Chen WH, Kline Leidy N. Development and first validation of the COPD Assessment Test. Eur Respir J 2009;34:648-54.

16. ATS Committee on Proficiency Standards for Clinical Pulmonary Function Laboratories. ATS statement: guidelines for the six-minute walk test. Am J Respir Crit Care Med 2002;166:1117.

17. Zhan S, Cerny FJ, Gibbons WJ, Mador MJ, Wu YW. Development of an unsupported arm exercise test in patients with chronic obstructive pulmonary disease. J Cardiopulm Rehabil 2006; 26:180-90.

18. Berg KO, Wood-Dauphinee SL, Williams JI, Maki B. Measuring balance in the elderly: validation of an instrument. Can J Public Health 1992;83 Suppl 2:S7-11.

19. Cachupe WJ, Shifflett B, Kahanov L, Wughalter EH. Reliability of biodex balance system measures. Meas Phys Educ Exerc Sci 2001;5:97-108.

20. Washburn RA, Smith KW, Jette AM, Janney CA. The Physical Activity Scale for the Elderly (PASE): development and evaluation. J Clin Epidemiol 1993;46:153-62.

21. Eser S, Saatli G, Eser E, Baydur H, Fidaner C. [The reliability and validity of the Turkish Version of the World Health Organization Quality of Life Instrument-Older Adults Module (WHOQOL-Old)]. Turk Psikiyatri Derg 2010;21:37-48.

22. Mills DE, Johnson MA, Barnett YA, Smith WH, Sharpe GR. The effects of inspiratory muscle training in older adults. Med Sci Sports Exerc 2015;47:691-7.

23. Gosselink R, De Vos J, van den Heuvel SP, Segers J, Decramer M, Kwakkel G. Impact of inspiratory muscle training in patients with COPD: what is the evidence? Eur Respir J 2011;37:41625.

24. Geddes EL, O'Brien K, Reid WD, Brooks D, Crowe J. Inspiratory muscle training in adults with chronic obstructive pulmonary disease: an update of a systematic review. Respir Med 2008;102: 
1715-29.

25. Saglam M, Arikan H, Vardar-Yagli N, Calik-Kutukcu E, Inal-Ince $\mathrm{D}$, Savci S, et al. Inspiratory muscle training in pulmonary arterial hypertension. J Cardiopulm Rehabil Prev 2015;35:198-206.

26. Huang CH, Yang GG, Wu YT, Lee CW. Comparison of inspiratory muscle strength training effects between older subjects with and without chronic obstructive pulmonary disease. J Formos Med Assoc 2011;110:518-26.

27. Takeda K, Kawasaki Y, Yoshida K, Nishida Y, Harada T, Yamaguchi $\mathrm{K}$, et al. The 6-minute pegboard and ring test is correlated with upper extremity activity of daily living in chronic obstructive pulmonary disease. Int J Chron Obstruct Pulmon Dis 2013; 8:347-51.

28. Vorrink SN, Kort HS, Troosters T, Lammers JW. Level of daily physical activity in individuals with COPD compared with healthy controls. Respir Res 2011;12:33.
29. Petrovic M, Reiter M, Zipko H, Pohl W, Wanke T. Effects of inspiratory muscle training on dynamic hyperinflation in patients with COPD. Int J Chron Obstruct Pulmon Dis 2012;7:797-805.

30. Aznar-Lain S, Webster AL, Canete S, San Juan AF, Lopez Mojares LM, Perez M, et al. Effects of inspiratory muscle training on exercise capacity and spontaneous physical activity in elderly subjects: a randomized controlled pilot trial. Int J Sports Med 2007;28:1025-9.

31. Jones GL. Quality of life changes over time in patients with chronic obstructive pulmonary disease. Curr Opin Pulm Med 2016;22:125-9.

32. Albuquerque IM, Rossoni CS, Cardoso DM, Paiva DN, Fregonezi G. Effects of short inspiratory muscle training on inspiratory muscle strength and functional capacity in physically active elderly: a quasi-experimental study. EurJ Physiother 2013;15:11-7. 